\title{
Low persistence in nature of captive reared rabbits after restocking operations
}

\author{
V. Piorno ${ }^{1} \cdot$ R. Villafuerte ${ }^{2,3}$ - M. Branco ${ }^{4}$ - M. Carneiro ${ }^{4,5} \cdot$ N. Ferrand $^{4,5}$. \\ P. C. Alves ${ }^{4,5,6}$
}

Received: 3 March 2015 /Revised: 24 May 2015 / Accepted: 26 May 2015 / Published online: 4 June 2015

(C) Springer-Verlag Berlin Heidelberg 2015

\begin{abstract}
The use of restocking of animals is common practice in the management of populations subject to hunting or recreational fishing. This practice encompasses the release of large numbers of individuals in an area where the species already exists, and thus it can have detrimental genetic impacts on the target populations, especially when captivereared animals are involved. To better understand this practice and its conservation implications, we chose as a model the wild rabbit (Oryctolagus cuniculus), a species of high economic and ecological importance, and often under intense management for hunting or conservation purposes, particularly after the large decline caused by rabbit hemorrhagic disease in the 90 's. We studied the genetics of rabbit populations in an area where restocking with captive, wild-domestic hybrids was common. We collected a total of 503 samples from 15
\end{abstract}

Communicated by M. Scandura

V. Piorno

vicente.piorno.gonzalez@xunta.es

1 Parque Nacional de las Islas Atlánticas de Galicia, Calle Oliva, 3, 36202 Vigo, Spain

2 Instituto de Estudios Sociales Avanzados (IESA-CSIC), Campo Santo de los Mártires n 7, 14004 Córdoba, Spain

3 Departamento de Zoología, Campus de Rabanales, Universidad de Córdoba, 14071 Córdoba, Spain

4 CIBIO/InBIO, Universidade do Porto, Campus de Vairão, 4485-661 Vairão, Portugal

5 Departamento de Biologia, Faculdade de Ciências da Universidade do Porto, Rua do Campo Alegre, S/N, Edifício FC4, 4169-007 Porto, Portugal

6 Wildlife Biology Program, University of Montana, Missoula, MT, USA hunting estates that had experienced differing restocking levels, as well as from five locations with no historical restocking and five game farms. All samples were analyzed to determine the mitochondrial DNA (mtDNA) lineage typical of the two European wild rabbit subspecies and domestic rabbit. Game farms and never restocked populations were very different in their haplotypic composition. In restocked areas, the proportion of the domestic lineage was higher when releases were recent and repeated, but this declined rapidly over time, in part due to selective removal by hunting. The extended use of this practice, considering the pronounced genetic and genotypic differences between domestic and wild rabbits, represents a potential danger to natural populations, especially given the marked decrease in wild rabbit numbers experienced in recent years in its original distribution range.

Keywords Captive breeding $\cdot$ Hunting $\cdot$ Hybrids . Oryctolagus cuniculus $\cdot$ Restocking $\cdot$ Wild rabbit

\section{Introduction}

The release of wild born or captive-bred animals is widely used to manage wildlife populations (Champagnon et al. 2012; Fischer and Lindenmayer 2000). Translocations are a controversial measure due to their generally low success (Armstrong and Seddon 2008), their high economic costs, and the genetic, ecological, and health risks linked to them (Cunningham 1996; Laikre et al. 2010; Naish et al. 2007). In particular, genetic consequences of releases such as the loss of genetic diversity, changes in population structure, and breakdown of adaptations have been well studied (Weeks et al. 2011).

There is growing awareness of the effects of animal translocations, to the point that the World Conservation Union 
(IUCN) only recommends releases when there are no alternatives for population recovery (IUCN/SSC 2013). This is the case of endangered species, where research has improved the design and implementation of conservation measures (Jule et al. 2008; Seddon et al. 2007). However, the situation is different for harvested populations, where restocking - the release of individuals in an area occupied by an existing conspecific population (Armstrong and Seddon 2008) - is frequently used with the aim of artificially sustaining higher harvest levels (Blanco-Aguiar et al. 2008; Champagnon et al. 2013). The large numbers of individuals released, and the little attention paid to their origin increases the risks of these operations.

Due to the large number of individuals demanded by hunting estates, restocking increasingly relies on captive breeding. These captive-reared animals often have lower genetic diversity and exhibit higher rates of inbreeding than wild populations as they become adapted to captive life (Williams and Hoffman 2009; Witzenberger and Hochkirch 2011). These features compromise survival and reproduction in the wild, and as a result, released individuals of captive origin have higher mortality rates than wild ones (Robert 2009). Among the reasons for this differential, mortality is a greater vulnerability to starvation, predation, or disease (Jule et al. 2008; Metcalfe et al. 2003). Also, in the case of populations restocked for hunting and sport fishing purposes, released individuals are often more easily harvested (Klefoth et al. 2013; Mezzera and Largiader 2001). All these detrimental attributes are genetically transmissible to resident populations (Lynch and O'Hely 2001; Theodorou and Couvet 2004), increasing the potential risks of restocking.

The European wild rabbit (Oryctolagus cuniculus) is a species that plays an important economic and ecological role in southwestern Europe (Delibes-Mateos et al. 2014), being the most important small game species and the main prey of a variety of threatened species in Mediterranean ecosystems, such as the Iberian Lynx (Lynx pardinus) and the Imperial Eagle (Aquila heliaca). Due to the decrease of rabbit abundance, mainly caused by viral diseases (myxomatosis and rabbit hemorrhagic disease, RHD) and changes in its habitat (Delibes-Mateos et al. 2009; Ferreira et al. 2010), large scale releases are carried out routinely, and as many as 500,000 rabbits are released each year in Spain and France (Calvete et al. 1997; Ward 2005). This practice, traditionally used by hunters (Delibes-Mateos et al. 2008), is now also employed by conservationists to support recovery programs for threatened species that rely on the rabbit for food (Moreno et al. 2004).

Rabbit restocking has been the subject of several studies, mainly focusing on its effectiveness in recovering wild populations (Cabezas et al. 2011; Calvete et al. 2005; Letty et al. 2003; Rouco et al. 2010). However, its potential impact on rabbit genetic diversity and structure has only recently received attention. In the Iberian Peninsula, the wild rabbit has two well-differentiated genetic lineages, $\mathrm{A}$ and $\mathrm{B}$, which correspond to two distinct subspecies (Oryctolagus cuniculus algirus and Oryctolagus cuniculus cuniculus, respectively). Within each lineage, there is a high degree of genetic diversity, with a well-defined geographic structure (Branco et al. 2000; Carneiro et al. 2010; Carneiro et al. 2013). Domestic rabbits, however, originated entirely from lineage $\mathrm{B}$ and exhibit a much lower genetic diversity (Carneiro et al. 2014; Queney et al. 2002).

Previous studies, based on mitochondrial DNA (mtDNA), have suggested that frequent harvesting and translocation of wild rabbits across the distribution ranges of the two lineages might impact the genetic structure of the species (DelibesMateos et al. 2008). However, Carneiro et al. (2013), in a study of the patterns of allele frequency change for a larger number of markers (including mtDNA), demonstrated that introgression between the two rabbit subspecies is widespread, although its incidence is low in the case of the mtDNA. According to this study, the observed mismatched haplotypes are more compatible with natural processes associated with secondary contact after a period of isolation and subsequent gene flow. This also indicates that for a large portion of the distribution of the species, the impact of restocking on the genetic composition of wild populations may have been minimal.

However, this broad scale pattern may be characterized by frequent exceptions at a more local scale. This is so because even though rabbit restocking generally involves the release of wild-caught animals, the use of captive-bred rabbits is not uncommon (Rogers et al. 1994; Sánchez García-Abad et al. 2012) especially in the north of the Iberian Peninsula (Navarro-Gonzalez et al. 2010; Piorno 2006). In this region, because wild donor populations are often scarce, captive breeding of wild-domestic hybrids to increase productivity is frequently employed (Piorno 2007). These operations can affect not just the success of the releases but also have possible negative effects on the recipient wild populations. Unlike translocations with wild individuals, the release of captivebred rabbits has not received enough attention.

In this paper, we evaluate, using genetic markers, the persistence of restocked rabbits with captive breeding origin in the wild. Our study area, the NW of the Iberian Peninsula, is well suited for this purpose, due to the frequent use of wilddomestic hybrid rabbits in restocking operations. Also, based on the genetic structure of the species (Carneiro et al. 2013; Queney et al. 2002), we expected to find enough differences between domestic and resident wild rabbits to measure the effect of releases. Under these premises, we sampled game farms and hunting estates that had been restocked at different intensities. Samples were obtained during the hunting season and the proportion of rabbits of captive origin monitored. We expected to observe (i) a marked genetic difference between game farms and natural sites (without restocking); (ii) a higher 
proportion of rabbits of captive origin in hunting estates where the intensity of restocking was higher; and (iii) a decreasing proportion of rabbits of captive origin along the hunting season, indicating their selective removal by hunting.

\section{Methods}

\section{Study area}

The study was carried out in hunting estates in Galicia (NW Iberian Peninsula, Fig. 1), during the 1999 hunting season (October-December). Restocking with captive-bred rabbits to increase huntable numbers of animals is regularly carried out in this area. Briefly, rabbits were bred in game farms using the same techniques as for meat rabbit production. Animals were reared in cages and spent a short pre-release acclimatization period in an open area. Because female wild rabbits are difficult to rear in captivity (Gonzalez-Redondo 2003), domestic females were crossed with wild males to increase productivity. The resulting offspring were backcrossed with wild males to obtain rabbits morphologically very similar to the wild ones (Piorno 2007). Rabbits were routinely vaccinated against myxomatosis and RHD before release. Rabbits are usually released in small groups (5-10 individuals) in natural refuges (abandoned warrens or areas with high vegetation cover).

\section{Sampling design}

Samples were taken in hunting estates that differed in their restocking history. Because restocking records in these estates are poorly maintained, we interviewed local hunters to ascertain whether releases had been carried out during two previous 4-year periods - hunting plans are valid for 4 years (Piorno 2006) - and during the year of sampling. With this information, we were able to establish three categories of restocked hunting estates (Table 1): (R1) estates that stopped restocking more than 4 years ago; (R2) estates that had been restocked until the last 4-year period, but not the year of sampling; and (R3) estates that had been restocked until the year of sampling. We were not able to estimate the number of released rabbits, as this information was not always available. To determine the genetic composition of the original wild populations and of the captive-bred animals, we sampled wild populations where restocking had never been reported (R0) and rabbits from captive rearing facilities that supplied the animals for restocking (CR), respectively. To take into account the possible effect of differences in rabbit abundance among hunting estates, we used an index of relative abundance. We calculated this index during the year of sampling and prior to the hunting season, by counting the number of latrines along five randomly-placed transects of $3000 \mathrm{~m}$ in each of the studied hunting estates (Iborra and Lumaret 1997).

\section{Sample collection and processing}

Five sites were selected at random in each of the five categories, and rabbits were sampled in each one by requesting hunters to collect tissue samples from hunted rabbits during the hunting season (October to December). A total of 503 rabbits from 25 locations were sampled. We divided the hunting season into five biweekly periods to monitor a possible change in the proportion of rabbits of captive origin occurring throughout the length of the hunting season.

From each hunted rabbit, we collected a portion of the ear and preserved it in $100 \%$ ethanol. To distinguish between the different mtDNA haplotypes (lineages $\mathrm{A}$ and $\mathrm{B}$ ), we used a previously described restriction fragment length polymorphisms (RFLPs) method (Branco et al. 2000).

\section{Data analysis}

We distinguished between captive-bred individuals and their wild counterparts by using existing information on the genetic distinctiveness of the species. We expected that lineage A would predominate in the original rabbit populations, because of the composition of the geographically closest populations (Fig. 1) and the direction of the routes of expansion of the two lineages proposed by Branco et al. (2002). Conversely, considering that domestic females are at the origin of most of the captive bred rabbits in this region, we expected that they would belong predominantly to lineage $\mathrm{B}$, namely to haplotypes $\mathrm{B} 1 \mathrm{Rba}$ and $\mathrm{B} 3 \mathrm{Rba}$ which are highly prevalent among domestic rabbits (Branco et al. 2000; Queney et al. 2002).

We used GLMs to test for differences among restocking categories in the variables of interest (McCullagh and Nelder 1989). All statistical analysis was performed using R 2.15.1 (R Core Team 2012).

\section{Results}

\section{Genetic characterization}

Haplotypes found in each sampling site and their proportions are listed in Table 2. As expected, lineage B haplotypes predominated in the captive rearing facilities (B1Rba; $63.4 \%$, $\mathrm{SE}=4.8 \%$ and $\mathrm{B} 3 \mathrm{Rba} ; 33.6 \%, \mathrm{SE}=4.7 \%$ ), and only one haplotype of lineage $\mathrm{A}(\mathrm{A} 2 \mathrm{Rba})$ was present, although at a low percentage $(3 \%, \mathrm{SE}=1.7 \%)$. In contrast, in the $\mathrm{R} 0$ sites, the frequency of the two B haplotypes found in farms was very low (B1Rba; $3 \%, \mathrm{SE}=1.7 \%$ and $\mathrm{B} 3 \mathrm{Rba} ; 0 \%$ ). In rabbits from these sites, the most common haplotypes were A2Rba $(69.0 \%, \mathrm{SE}=4.6 \%)$ and $\mathrm{ARb} 4(16.0 \%, \mathrm{SE}=3.6 \%)$, which 
Fig. 1 Map showing: a the distribution in the Iberian Peninsula of the proportion of mitochondrial haplotypes of the lineage A, B1Rba and B3Rba (HDO), and the rest of the haplotypes of lineage $\mathrm{B}(\mathrm{Bw})$, according to Branco et al. (2000), and $\mathbf{b}$ the location of the sampling sites in the study area and the proportions of the studied mitochondrial haplotypes
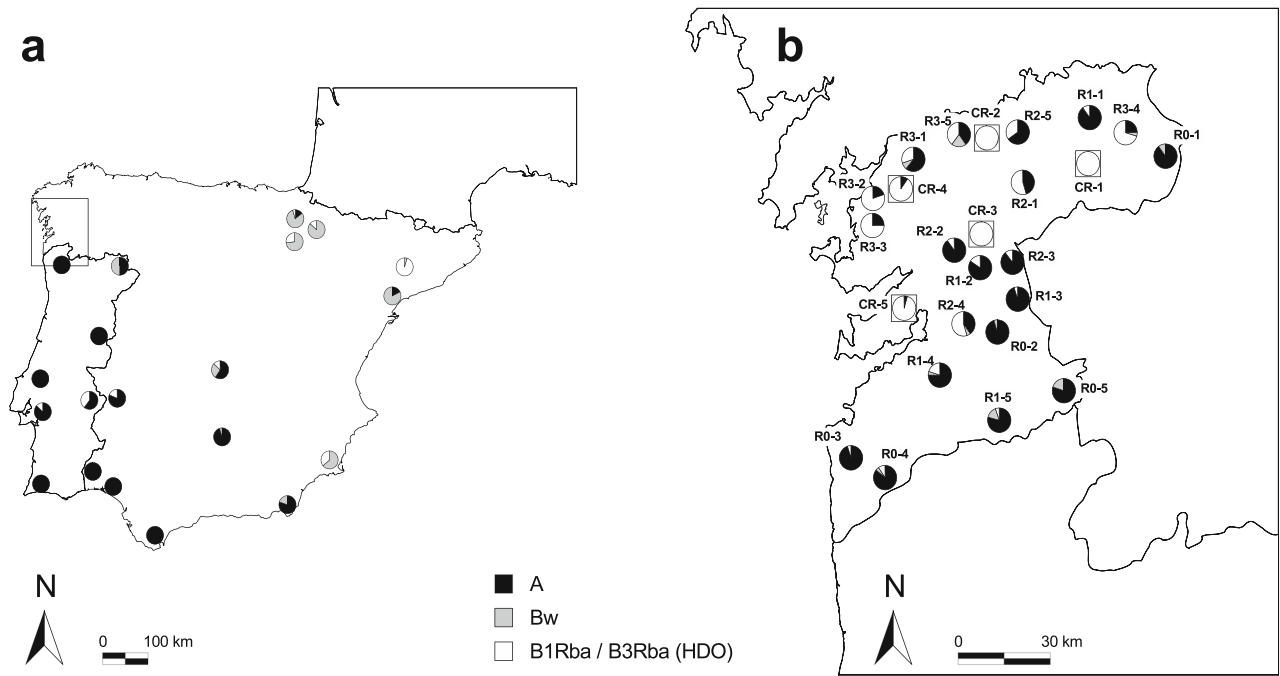

coexisted with low proportions of other five haplotypes. The remaining wild populations (R1, R2, and R3) were dominated by the four main haplotypes found in R0 (A2Rba; ARb4) and CR (B1Rba; B3Rba) sites (Table 2).

\section{Effect of restocking history and rabbit abundance}

A GLM with a binomial error distribution and logit link was used to test the effects of restocking history and rabbit abundance on the proportion of haplotypes of potential domestic origin (HDO, B1Rba, and B3Rba) in wild populations. Only restocking history had a significant effect $\left(\mathrm{F}_{3,16}=10.716, P=\right.$ $0.001)$, while the effect of abundance $\left(\mathrm{F}_{1,15}=0.100, P=0.757\right)$ and the interaction between the two factors $\left(\mathrm{F}_{3,12}=0.541, P=\right.$ 0.664 ) were not significant.

Overall, the frequency of HDO is higher in sites with higher restocking levels (Fig. 2). Pooling all sampling sites in each category, the proportions of these haplotypes were $11.1 \%(\mathrm{SE}=3.2 \%)$ in $\mathrm{R} 1,33.3 \%(\mathrm{SE}=4.7 \%)$ in $\mathrm{R} 2$, and $58.3 \%$ ( $\mathrm{SE}=4.9 \%)$ in $\mathrm{R} 3$. The variability of $\mathrm{HDO}$ proportion was also higher in the more restocked categories. In sites that were never restocked (R0), the HDO proportion was $3.0 \%$

Table 1 Classification of sampling sites according to the occurrence of restocking during the identified periods

\begin{tabular}{llll}
\hline \multirow{2}{*}{ Restocking category } & \multicolumn{2}{l}{ Restocking history } \\
\cline { 2 - 4 } & $1992-1995$ & $1996-1998$ & 1999 \\
\hline R0 & No & No & No \\
R1 & Yes & No & No \\
R2 & Yes & Yes & No \\
R3 & Yes & Yes & Yes \\
CR & Captive rearing facilities & \\
\hline
\end{tabular}

( $\mathrm{SE}=1.7 \%$ ), which was statistically different from $\mathrm{R} 1$ sites (Fisher exact test, $P=0.027$ ).

Differences in rabbit abundance were detected among restocking history categories, revealed by means of a GLM with a Poisson error distribution and logarithmic link $\left(\mathrm{F}_{3,16}=\right.$ 3.392, $P=0.041$ ). Rabbit abundance was higher in the least intensively restocked sites (Fig. 3).

\section{Effect of hunting date}

The proportion of HDO varied along the hunting season in the more intensively restocked sites. A GLM with a binomial error distribution and logit link revealed a significant effect of the interaction between biweekly sampling period and restocking history on $\mathrm{HDO}$ proportion $\left(\mathrm{F}_{3,58}=3.178, P=\right.$ $0.023)$. There was a marked decline in the proportion of HDO from the first to the fifth biweekly period in R2 and R3 sites, but not in the R0 and R1 sites (Fig. 4).

\section{Discussion}

\section{Differences between captive-reared and wild rabbits}

Our results showed a marked difference in haplotypic composition between animals from captive breeding centers and from wild populations that were never restocked. The sites without restocking (R0) exhibited the expected genetic pattern for natural populations in this region (Branco et al. 2002), with very low proportions of B1Rba and B3Rba haplotypes, which could be explained most likely by natural levels of introgression but also by undocumented releases or dispersal from neighboring restocked areas. The crossbreeding system practiced by game farmers, using wild males and domestic females as breeders, would explain the low occurrence of wild 
Table 2 Relative frequencies of mitochondrial haplotypes in each of the sampling sites and restocking categories

\begin{tabular}{|c|c|c|c|c|c|c|c|c|c|c|c|c|c|c|}
\hline \multirow[t]{3}{*}{ Code } & \multirow[t]{3}{*}{ Site name } & \multirow[t]{3}{*}{$\mathrm{N}$} & \multicolumn{12}{|c|}{ Haplotypes } \\
\hline & & & \multicolumn{5}{|c|}{ Lineage A } & \multicolumn{7}{|c|}{ Lineage B } \\
\hline & & & $\mathrm{A} 2 \mathrm{Rba}$ & ARb4 & A1Rba & ARb15 & Arb17 & B11Rba & B8Rba & BRb1 & BRb10 & BRb12 & B1Rba & B3Rba \\
\hline R0-1 & Areosa & 20 & 0.65 & 0.25 & & & & 0.10 & & & & & & \\
\hline R0-2 & Traspielas & 20 & 0.60 & 0.20 & 0.15 & & & & & & 0.05 & & & \\
\hline R0-3 & Groba & 20 & 0.90 & & & 0.05 & & & & & & & 0.05 & \\
\hline R0-4 & Argallo & 21 & 0.76 & 0.10 & & & & & & & 0.05 & & 0.10 & \\
\hline \multirow[t]{2}{*}{ R0-5 } & Crecente & 20 & 0.55 & 0.25 & & & & & 0.20 & & & & & \\
\hline & Subtotal & 101 & 0.69 & 0.16 & 0.03 & 0.01 & & 0.02 & 0.04 & & 0.02 & & 0.03 & \\
\hline R1-1 & Carrio & 20 & 0.50 & 0.40 & & & & & & & & & 0.05 & 0.05 \\
\hline R1-2 & Caveiro & 20 & 0.37 & 0.47 & & & & & & & & & 0.05 & 0.11 \\
\hline R1-3 & A Laxe & 20 & 0.60 & 0.35 & & & & & & & & & 0.05 & \\
\hline R1-4 & Mos & 20 & 0.55 & 0.05 & 0.15 & & & & 0.05 & & & & 0.10 & 0.10 \\
\hline \multirow[t]{2}{*}{ R1-5 } & As Neves & 19 & 0.32 & 0.47 & & & & & & & 0.16 & & 0.05 & \\
\hline & Subtotal & 99 & 0.47 & 0.35 & 0.03 & & & & 0.01 & & 0.03 & & 0.06 & 0.05 \\
\hline R2-1 & Forcarei & 20 & 0.20 & 0.20 & 0.05 & & & & & & & & 0.20 & 0.35 \\
\hline R2-2 & Castelo & 20 & 0.25 & 0.65 & & & & & & & & & 0.05 & 0.05 \\
\hline R2-3 & Xesta & 19 & 0.26 & 0.63 & & & & & & & & & & 0.11 \\
\hline R2-4 & Pazos & 20 & 0.15 & 0.20 & & & 0.05 & & & & 0.05 & & 0.45 & 0.10 \\
\hline \multirow[t]{2}{*}{ R2-5 } & A Rocha & 20 & 0.40 & 0.25 & & & & & & & & & 0.20 & 0.15 \\
\hline & Subtotal & 99 & 0.25 & 0.38 & 0.01 & & 0.01 & & & & 0.01 & & 0.18 & 0.15 \\
\hline R3-1 & Xiabre & 23 & & 0.61 & & & & & & & 0.04 & 0.04 & 0.22 & 0.09 \\
\hline R3-2 & Baión & 20 & & 0.20 & & & & & & & & & 0.60 & 0.20 \\
\hline R3-3 & Meis & 20 & & 0.25 & & & & & & & & & 0.55 & 0.20 \\
\hline R3-4 & Alperiz & 20 & 0.10 & 0.15 & & & & & & & 0.05 & & 0.45 & 0.25 \\
\hline \multirow[t]{2}{*}{ R3-5 } & Fians & 20 & 0.20 & 0.20 & & & & 0.10 & & 0.10 & & & & 0.40 \\
\hline & Subtotal & 103 & 0.06 & 0.29 & & & & 0.02 & & 0.02 & 0.02 & 0.01 & 0.36 & 0.22 \\
\hline CR-1 & Lalín & 20 & & & & & & & & & & & 0.70 & 0.30 \\
\hline CR-2 & Estrada & 21 & & & & & & & & & & & 0.71 & 0.29 \\
\hline CR-3 & Cotobade & 20 & & & & & & & & & & & 0.75 & 0.25 \\
\hline CR-4 & Rubiáns & 20 & 0.10 & & & & & & & & & & 0.15 & 0.75 \\
\hline \multirow[t]{2}{*}{ CR-5 } & Castiñeira & 20 & 0.05 & & & & & & & & & & 0.85 & 0.10 \\
\hline & Subtotal & 101 & 0.03 & & & & & & & & & & 0.63 & 0.34 \\
\hline
\end{tabular}

haplotypes in these centers because of maternal transmission of mtDNA. Overall, while B1Rba and B3Rba haplotypes cannot be considered diagnostic at the individual level, the unusually high frequency in some localities within our study area can be considered a reliable index of restocking intensity.

\section{Persistence of restocked rabbits}

The marked difference in genetic composition allowed us to detect the presence of captive-origin rabbits in all samples from restocked areas, suggesting an important effect of restocking on native populations in the studied region. The proportion of B1Rba and B3Rba haplotypes was in some cases very high compared to similarly managed species
(Barilani et al. 2005; Blanco-Aguiar et al. 2008; Champagnon et al. 2013). This is occurring in spite of the low survival observed in releases carried out by hunters with rabbits of wild origin (Calvete et al. 1997). Moreover, we should expect a lower survival in our case, considering that captive individuals are being used, and these usually have a higher post-release mortality (Beck et al. 1994; Fischer and Lindenmayer 2000). Our results suggest that the high prevalence of domestic origin haplotypes is a consequence of intensive and repeated restocking. The highest values of B1Rba and B3Rba haplotypes are found in the intensively restocked R2 and R3 hunting states. The chosen categories of restocking indicate how much time has elapsed since the last release, but also the recurrence of this management measure. It seems reasonable 


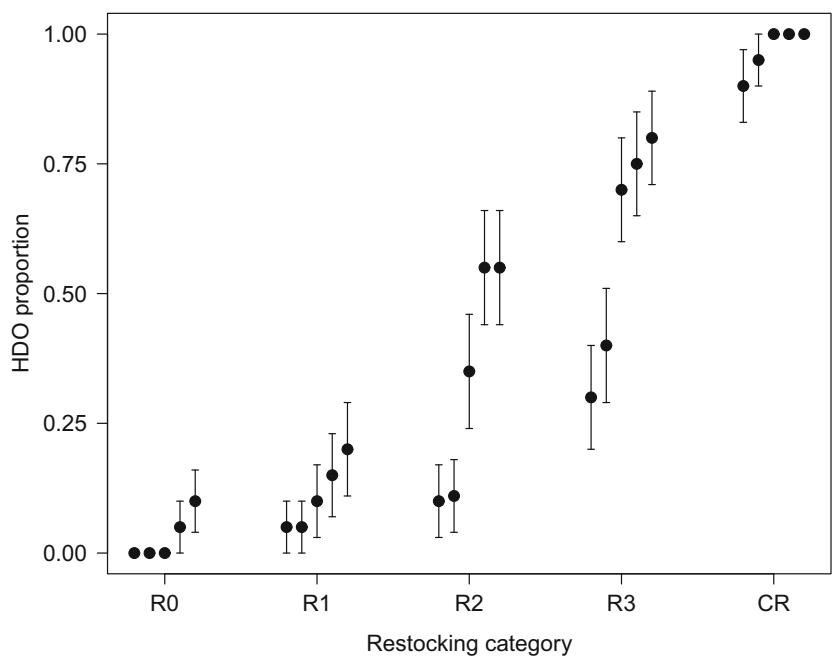

Fig. 2 Proportion of haplotypes of domestic origin (HDO) in each of the sampling sites, grouped by restocking category. Error bars represent one standard error

to expect that more releases will increase restocking success, as has been previously shown (Fischer and Lindenmayer 2000). But time since the last release, and its effect on survival of released rabbits, may also play a role. R2 and R3 sites, both repeatedly restocked, differ only in whether or not releases were carried out the year of sampling, and the difference in $\mathrm{B} 1 \mathrm{Rba}$ and B3Rba haplotypes between them is very pronounced. This suggests that recent releases have a pronounced effect on the proportion of B1Rba and B3Rba haplotypes and that this effect declines rapidly if restocking efforts are not maintained.

In spite of the observed decrease over time in the proportion of released rabbits, we found that the sites that had not been restocked for at least 5 years (R1) had a higher HDO proportion from those sites that were never restocked (R0). Due to the limited diagnostic value of our markers, we cannot

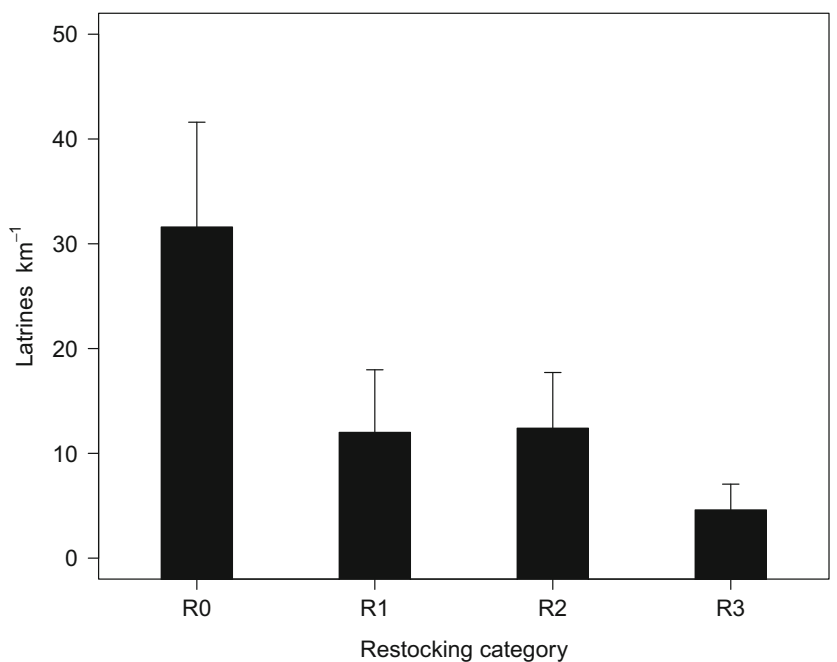

Fig. 3 Rabbit abundance for the different restocking categories. Error bars represent one standard error

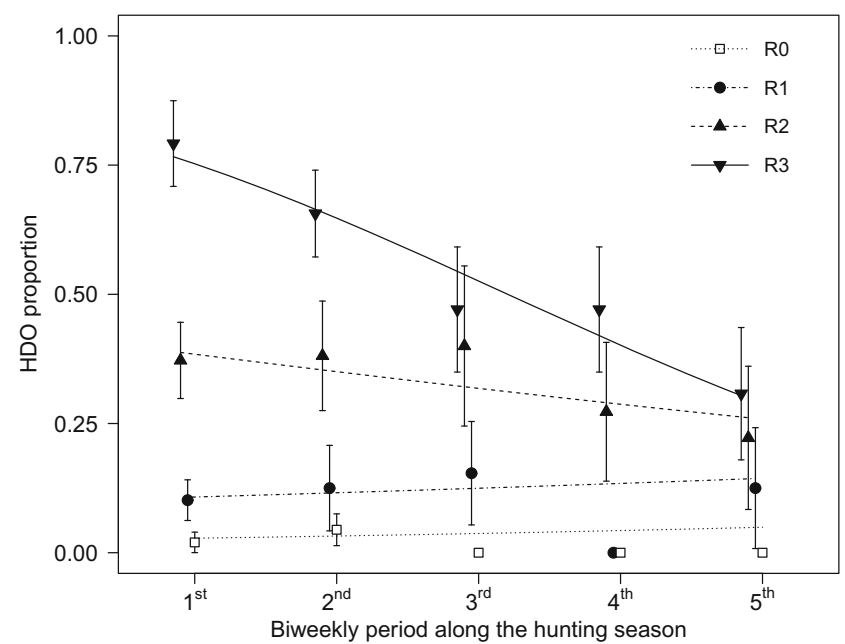

Fig. 4 Evolution of the HDO proportion along the hunting season in the different restocking categories. Each dot represents HDO proportion for a given restocking category and biweekly period. Error bars represent one standard error. Trend lines were fitted using the coefficients of the GLM

completely rule out natural introgression as a cause of this difference. But, this result could also indicate that the domestic lineage can persist in the long-term at low proportions, either by survival of the released rabbits - rabbit longevity in the wild may exceed 8 years (Gibb and Morgan-Williams 1994) — or by their reproduction.

\section{Effect of hunting on persistence}

The decreasing proportion of B1Rba and B3Rba haplotypes along the hunting season, more evident in recently restocked zones, is most likely explained by the likelihood that rabbits of putative domestic origin are more easily hunted. This effect is especially evident where rabbits have been recently released and tends to decrease over time, suggesting that surviving rabbits are less sensitive to hunting. This type of effect has been documented in other restocked species in both sport fishing (brown trout Salmo trutta, Mezzera and Largiader 2001; common carp Cyprinus carpio, Klefoth et al. 2013); and hunting (mallard Anas platyrhynchos, Legagneux et al. 2009). We cannot completely rule out a different mortality rate in released and resident rabbits due to natural causes, like predation or disease, but we consider it less likely. According to the available information, rabbits are released in the study area mostly in late spring and summer, several months before the onset of the hunting season. Previous studies have shown that this period is sufficient to allow acclimatization and that would equalize mortality rates between introduced and resident rabbits (Calvete and Estrada 2004; Letty et al. 2002; Rouco et al. 2008). In addition, released rabbits in our study area were vaccinated against myxomatosis and RHD, the two main causes of mortality in wild rabbits. We should expect then a lower mortality in the released hybrid individuals, since commercial vaccines are successful in protecting rabbits from 
these diseases in the field (Cabezas et al. 2006; Calvete et al. 2004; Ferreira et al. 2009).

While this result would suggest that hunting may be heavier upon the captive-bred rabbits, and that the observed proportions may be an overestimation of their actual abundance, it also constitutes per se an important finding. Here, we identify a potential source of mortality of restocked rabbits that has never been reported to our knowledge in a hunted mammal.

\section{Conservation implications}

As it happens with other species (Barilani et al. 2005; Blanco-Aguiar et al. 2008), the release of large numbers of captive-bred individuals with hunting purposes poses a risk for the conservation of the wild rabbit. The productive capacity of Spanish game farms has been estimated at around 225,000 rabbits per annum (Sánchez García-Abad et al. 2012). Therefore, captive rabbits represent an important proportion of the total of 500,000 rabbits released annually in Spain (Calvete et al. 1997; Ward 2005). As shown in this study and others (González-Redondo and Sánchez-Martínez 2014), many game farms pay little attention to the genetic origin of their breeding animals. The lack of attention to this issue can potentially have a major impact on the genetic composition of wild rabbit populations. Repeated releases of captive individuals will no doubt lead to genetic displacement and introgression, particularly in low density populations, where the ratio of captive-bred to resident is lower and, as shown in this study, restocking is more common. We therefore strongly advise against the release of captive hybrid rabbits, recommending the use of individuals of wild origin instead, either wild caught or from extensive breeding enclosures (Guerrero-Casado et al. 2013b).

We have also found that the more intensively restocked categories show the lowest rabbit abundances, which is coherent with the limited ability of releases to increase abundance documented for this and other species (Diaz-Fernandez et al. 2013; Moreno et al. 2004; Young 2013). In addition, hybrid rabbits between the two subspecies have lower reproductive fitness, which can further contribute to lower abundance (Carneiro et al. 2013).

Considering the apparent low contribution made by these animals to the abundance of rabbits in hunting estates, and the perception of their low efficacy by managers (Delibes-Mateos et al. 2008), it is rather paradoxical that restocking is still widely used. The finding in the present study that released rabbits are more likely to be hunted may partially explain this paradox. Thus, while hunters usually prefer wild individuals over farm-reared ones (Delibes-Mateos et al. 2014), by using releases they can artificially maintain populations which, due to the ease of capture, also provide higher hunting yields than wild populations at the same density. In situations like these, restocking cannot be regarded as a sustainable management strategy (Guerrero-Casado et al. 2013a) and should be replaced by other tools, e.g., habitat management (Ferreira and Alves 2009; Ferreira et al. 2014), in order to promote the longterm recovery of wild populations.

Acknowledgments We wish to thank Javier Nogueira, José Touceda, and numerous hunters, wildlife officers and game farm owners for their help in obtaining the samples. We are grateful to Alvaro Moraña for their help in the field and laboratory work, and Dr. John Fa and two anonymous reviewers for their helpful comments on the manuscript. Genetic analysis was carried out with the support of the conservation project "Recuperación do coello de monte en Galicia" financed by Xunta de Galicia. This work was also partially supported by the research project CGL2013-43197-R, by POPH-QREN funds from the European Social Fund and Portuguese MCTES [FCT Investigator (IF/00283/2014) and postdoc grants to MC (SFRH/BPD/72343/2010) and MB (SFRH/BPD/ 40073/2007), and by FEDER funds through the COMPETE program and Portuguese national funds through the FCT - Fundação para a Ciência e a Tecnologia - (project PTDC/CVT/122943/2010).

\section{Compliance with ethical standards}

Funding All the sources of funding for this study are acknowledged in the previous acknowledgements section.

Conflict of interest The authors declare that they have no conflict of interest.

Ethical approval All applicable international, national, and/or institutional guidelines for the care and use of animals were followed. This article does not contain any studies with human participants performed by any of the authors.

Informed consent This article does not contain any studies with individual participants that required the obtainment of informed consent.

\section{References}

Armstrong DP, Seddon PJ (2008) Directions in reintroduction biology. Trends Ecol Evol 23:20-25

Barilani M, Deregnaucourt S, Gallego S et al (2005) Detecting hybridization in wild (Coturnix c. coturnix) and domesticated (Coturnix $c$. japonica) quail populations. Biol Conserv 126:445-455

Beck BB, Rapaport LG, Stanley Price MR, Wilson AC (1994) Reintroduction of captive-born animals. In: Olney PJS, Mace GM, Feistner ATC (eds) Creative conservation: Interactive management of wild and captive animals. Chapman \& Hall, London, pp 265-286

Blanco-Aguiar JA, González-Jara P, Ferrero ME et al (2008) Assessment of game restocking contributions to anthropogenic hybridization: the case of the Iberian red-legged partridge. Anim Conserv 11: 535-545

Branco M, Ferrand N, Monnerot M (2000) Phylogeography of the European rabbit (Oryctolagus cuniculus) on the Iberian Peninsula inferred from RFLP analysis of the cytochrome b gene. Heredity 85 : 307-317

Branco M, Monnerot M, Ferrand N, Templeton AR (2002) Postglacial dispersal of the European rabbit (Oryctolagus cuniculus) on the Iberian Peninsula reconstructed from nested glade and mismatch analyses of mitochondrial DNA genetic variation. Evolution 56: 792-803 
Cabezas S, Calvete C, Moreno S (2006) Vaccination success and body condition in the European wild rabbit: Applications for conservation strategies. J Wildl Manag 70:1125-1131

Cabezas S, Calvete C, Moreno S (2011) Survival of translocated wild rabbits: Importance of habitat, physiological and immune condition. Anim Conserv 14:665-675

Calvete C, Estrada R (2004) Short-term survival and dispersal of translocated European wild rabbits. Improving the release protocol. Biol Conserv 120:507-516

Calvete C, Villafuerte R, Lucientes J, Osacar JJ (1997) Effectiveness of traditional wild rabbit restocking in Spain. J Zool 241:271-277

Calvete C, Estrada R, Lucientes J, Osacar JJ, Villafuerte R (2004) Effects of vaccination against viral haemorrhagic disease and myxomatosis on long-term mortality rates of European wild rabbits. Vet Rec 155: 388-391

Calvete C, Angulo E, Estrada R et al (2005) Quarantine length and survival of translocated european wild rabbits. J Wildl Manag 69:10631072

Carneiro M, Blanco-Aguiar JA, Villafuerte R et al (2010) Speciation in the European rabbit (Oryctolagus cuniculus): Islands of differentiation on the X-chromosome and autosomes. Evolution 64:34433460

Carneiro M, Baird SJE, Afonso S et al (2013) Steep clines within a highly permeable genome across a hybrid zone between two subspecies of the European rabbit. Mol Ecol 22:2511-2525

Carneiro M, Rubin CJ, Di Palma F et al (2014) Rabbit genome analysis reveals a polygenic basis for phenotypic change during domestication. Science 345:1074-1079

Champagnon J, Elmberg J, Guillemain M et al (2012) Conspecifics can be aliens too: a review of effects of restocking practices in vertebrates. J Nat Conserv 20:231-241

Champagnon J, Crochet P-A, Kreisinger J et al (2013) Assessing the genetic impact of massive restocking on wild mallard. Anim Conserv 16:295-305

Cunningham AA (1996) Disease risks of wildlife translocations. Conserv Biol 10:349-353

Delibes-Mateos M, Ramirez E, Ferreras P, Villafuerte R (2008) Translocations as a risk for the conservation of European wild rabbit Oryctolagus cuniculus lineages. Oryx 42:259-264

Delibes-Mateos M, Ferreras P, Villafuerte R (2009) European rabbit population trends and associated factors: a review of the situation in the Iberian Peninsula. Mammal Rev 39:124-140

Delibes-Mateos M, Giergiczny M, Caro J et al (2014) Does hunters' willingness to pay match the best hunting options for biodiversity conservation? A choice experiment application for small-game hunting in Spain. Biol Conserv 177:36-42

Diaz-Fernandez S, Arroyo B, Casas F et al (2013) Effect of game management on wild Red-legged partridge abundance. Plos One 8: e66671

Ferreira C, Alves PC (2009) Influence of habitat management on the abundance and diet of wild rabbit (Oryctolagus cuniculus algirus) populations in Mediterranean ecosystems. Eur J Wildl Res 55:487496

Ferreira C, Ramírez E, Castro F, Ferreras P, Alves PC, Redpath S, Villafuerte R (2009) Field experimental vaccination campaigns against myxomatosis and their effectiveness in the wild. Vaccine 27:6998-7002

Ferreira C, Paupério J, Alves PC (2010) The usefulness of field data and hunting statistics in the assessment of wild rabbit (Oryctolagus cuniculus) conservation status in Portugal. Wildl Res 37:223

Ferreira C, Touza J, Rouco C et al (2014) Habitat management as a generalized tool to boost European rabbit Oryctolagus cuniculus populations in the Iberian Peninsula: a cost-effectiveness analysis. Mammal Rev 44:30-43

Fischer J, Lindenmayer DB (2000) An assessment of the published results of animal relocations. Biol Conserv 96:1-11
Gibb JA, Morgan-Williams J (1994) The rabbit in New Zealand. In: Thompson HV, King CM (eds) The European rabbit: the history and biology of a successful colonizer. Oxford University Press, Oxford, pp 158-204

Gonzalez-Redondo P (2003) Contribución al conocimiento de la producción del conejo silvestre (Oryctolagus cuniculus) en cautividad estricta. $\mathrm{PhD}$ dissertation, University of Córdoba

González-Redondo P, Sánchez-Martínez R (2014) Characterization of wild rabbit commercial game farms in Spain. World Rabbit Sci 22: 51

Guerrero-Casado J, Letty J, Tortosa FS (2013a) European rabbit restocking: a critical review in accordance with IUCN (1998) guidelines for re-introduction. Anim Biodivers Conserv 36:177-185

Guerrero-Casado J, Ruiz-Aizpurua L, Carpio AJ, Tortosa FS (2013b) Factors affecting wild rabbit production in extensive breeding enclosures: how can we optimize efforts? World Rabbit Sci 21:193-199

Iborra O, Lumaret JP (1997) Validity limits of the pellet group counts in wild rabbit (Oryctolagus cuniculus). Mammalia 61:205-218

IUCN/SSC (2013) Guidelines for reintroductions and other conservation translocations. Version 1.0. IUCN Species Survival Commission, Gland, Switzerland. https://portals.iucn.org/library/efiles/ documents/2013-009.pdf. Accessed 15 February 2015

Jule KR, Leaver LA, Lea SEG (2008) The effects of captive experience on reintroduction survival in carnivores: a review and analysis. Biol Conserv 141:355-363

Klefoth T, Pieterek T, Arlinghaus R (2013) Impacts of domestication on angling vulnerability of common carp, Cyprinus carpio: the role of learning, foraging behaviour and food preferences. Fish Manag Ecol $20: 174-186$

Laikre L, Schwartz MK, Waples RS et al (2010) Compromising genetic diversity in the wild: Unmonitored large-scale release of plants and animals. Trends Ecol Evol 25:520-529

Legagneux P, Inchausti P, Bourguemestre F et al (2009) Effect of predation risk, body size, and habitat characteristics on emigration decisions in mallards. Behav Ecol 20:186-194

Letty J, Hivert J, Queney G et al (2002) Assessment of genetic introgression due to a wild rabbit restocking. Z Jagdwiss 48:33-41

Letty J, Aubineau J, Marchandeau S, Clobert J (2003) Effect of translocation on survival in wild rabbit (Oryctolagus cuniculus). Mamm Biol 68:250-255

Lynch M, O'Hely M (2001) Captive breeding and the genetic fitness of natural populations. Conserv Genet 2:363-378

McCullagh P, Nelder JA (1989) Generalized linear models, 2nd edn. Chapman and Hall/CRC, Boca Raton

Metcalfe NB, Valdimarsson SK, Morgan IJ (2003) The relative roles of domestication, rearing environment, prior residence and body size in deciding territorial contests between hatchery and wild juvenile salmon. J Appl Ecol 40:535-544

Mezzera M, Largiader CR (2001) Evidence for selective angling of introduced trout and their hybrids in a stocked brown trout population. J Fish Biol 59:287-301

Moreno S, Villafuerte R, Cabezas S, Lombardi L (2004) Wild rabbit restocking for predator conservation in Spain. Biol Conserv 118: 183-193

Naish KA, Taylor JE, Levin PS et al (2007) An evaluation of the effects of conservation and fishery enhancement hatcheries on wild populations of salmon. Adv Mar Biol 53:61-194

Navarro-Gonzalez N, Serrano E, Casas-Diaz E et al (2010) Game restocking and the introduction of sarcoptic mange in wild rabbit in north-eastern Spain. Anim Conserv 13:586-591

Piorno V (2006) Gestión cinegética y conservación del conejo de monte. $\mathrm{Ph} . \mathrm{D}$. dissertation, University of Vigo

Piorno V (2007) Obtención de los conejos para la repoblación. In: Federación Galega de Caza (ed) Claves para el éxito en la mejora de las poblaciones de conejo en Galicia. Tecor de Portas, Spain, pp $70-95$ 
Queney G, Vachot AM, Brun JM et al (2002) Different levels of human intervention in domestic rabbits: Effects on genetic diversity. J Hered 93:205-209

R Core Team (2012) R: a language and environment for statistical computing. R Foundation for Statistical Computing, Vienna

Robert A (2009) Captive breeding genetics and reintroduction success. Biol Conserv 142:2915-2922

Rogers PM, Arthur CP, Soriguer RC (1994) The rabbit in continental Europe. In: Thompson HV, King CM (eds) The European rabbit: the history and biology of a successful colonizer. Oxford Univesity Press, Oxford, pp 22-63

Rouco C, Ferreras P, Castro F, Villafuerte R (2008) The effect of exclusion of terrestrial predators on short-term survival of translocated European wild rabbits. Wildl Res 35:625-632

Rouco C, Ferreras P, Castro F, Villafuerte R (2010) A longer confinement period favors European wild rabbit (Oryctolagus cuniculus) survival during soft releases in low-cover habitats. Eur J Wildl Res 56:215219

Sánchez García-Abad C, Alonso de la Varga ME, Díez Valle C, Gaudioso Lacasa VR (2012) An approach to the statistics of wild lagomorph captive rearing for releasing purposes in Spain. World Rabbit Sci 20: 49-56

Seddon PJ, Armstrong DP, Maloney RF (2007) Developing the science of reintroduction biology. Conserv Biol 21:303-312

Theodorou K, Couvet D (2004) Introduction of captive breeders to the wild: harmful or beneficial? Conserv Genet 5:1-12

Ward D (2005) Reversing rabbit decline: One of the biggest challenges for nature conservation in Spain and Portugal. IUCN Lagomorph Specialist Group, Gland, Switzerland, 1-54

Weeks AR, Sgro CM, Young AG et al (2011) Assessing the benefits and risks of translocations in changing environments: a genetic perspective. Evol Appl 4:709-725

Williams SE, Hoffman EA (2009) Minimizing genetic adaptation in captive breeding programs: a review. Biol Conserv 142:2388-2400

Witzenberger KA, Hochkirch A (2011) Ex situ conservation genetics: a review of molecular studies on the genetic consequences of captive breeding programmes for endangered animal species. Biodivers Conserv 20:1843-1861

Young KA (2013) The balancing act of captive breeding programmes: salmon stocking and angler catch statistics. Fish Manag Ecol 20:434-444 